\title{
Central natriuretic peptide receptor (NPR)-B and peripheral lipid accumulation
}

\author{
Rossi, Jari
}

2016-10

Rossi , J 2016 , ' Central natriuretic peptide receptor (NPR)-B and peripheral lipid accumulation ' , Peptides , vol. 84 , pp. 68-69 . https://doi.org/10.1016/j.peptides.2016.08.003

http://hdl.handle.net/10138/228500

https://doi.org/10.1016/j.peptides.2016.08.003

publishedVersion

Downloaded from Helda, University of Helsinki institutional repository.

This is an electronic reprint of the original article.

This reprint may differ from the original in pagination and typographic detail.

Please cite the original version. 
Editorial

\section{Central natriuretic peptide receptor (NPR)-B and peripheral lipid accumulation}

The natriuretic peptide family: atrial natriuretic peptide (ANP), brain natriuretic peptide (BNP), and C-type natriuretic peptide (CNP) have been traditionally considered as important mediators of cardiovascular regulation [1,2]. During physiological stress, circulating BNP has been also suggested to have predictive value for cardiopulmonary performance [3].

The physiological effects of natriuretic peptides are mediated by natriuretic peptide receptors NPR-A, NPR-B and NPR-C, which are expressed by a variety of tissues and cell types, for a review see [4]. From these, the A-receptor shows highest affinity for cardiac myocyte derived factors ANP and BNB, while NPR-B preferably binds CNP [5]. In addition to natriuretic peptide family's established role in the regulation of salt and water balance, this group of peptides seems to have wide-ranging effects on physiological functions.

For example, previous studies have shown that knockout of CNP (CNP-KO) or NPR-B leads to dwarfism and poor postnatal survival due to impaired endochondral formation [6,7]. Conversely, CNPKO mice with chondrocyte specific expression (and rescued skeletal dysplasia) show interesting phenotype with decreased food intake, body fat and increased energy expenditure and insulin sensitivity [8]. The potential role of CNP/NPR-B signaling in the regulation of energy balance is supported by findings that both CNP and NPR-B are expressed in hypothalamus, the central site for the regulation of food intake and energy expenditure $[9,10]$. In addition, intracerebroventricular administration of CNP can suppress food intake via activation of melanocortin system [11].

In the July issue of Peptides, Yamashita et al. describe the generation and phenotypic characterization of a mouse model with brain-specific NPR-B deficiency, and thus are able to study in more detail the neuronal role of CNP/NPR-B signaling in the regulation of energy balance [12]. To study this, the authors have employed Cre/loxP system by crossing Nestin-Cre mice together with floxed-NPR-B mice to generate brain-specific NPR-B deletion (BND-mice). Importantly, the authors have used independently generated Nestin-Cre mice, which do not appear to have similar growth associated physiological phenotype as reported earlier for this Cre-strain $[13,14]$.

The BND-mice generated by Yamashita et al. point to a more brain specific expression of Cre-transgene, as NPR-B expression

DOI of original article: http://dx.doi.org/10.1016/j.peptides.2016.03.014. in peripheral tissues studied (heart, liver, brown adipose tissue, white adipose tissue) remained unchanged. It should be noted that there was approximately $30 \%$ of NPR-B remaining at the mRNA level after Nestin-Cre mediated recombination in hypothalamus and cerebellum. The investigators report that BND mice are resistant to obesity, and protected from hepatic steatosis and lipid accumulation in mesenteric fat induced by high-fat diet (HFD). Importantly, the beneficial effects on lipid accumulation on HFD were observed while the food intake and energy expenditure were similar between WT and BND mice. Thus, the results suggest that either the remaining NPR-B expression is sufficient to mediate CNPs effects on energy balance or Cre-mediated recombination occurs only in a subpopulation, non-food intake/energy expenditure mediating hypothalamic neurons.

The findings raise an interesting question. How are the observed effects on lipid accumulation mediated to the peripheral tissues such as liver and adipose tissue? The most plausible mediator would be the sympathetic nervous system, which appears to be inhibited through central CNP/NPR-B signaling [8]. Is the common denominator an interplay with melanocortin system, which through specific brain nuclei with connections to autonomic nervous system is able to regulate food intake, energy expenditure, glucose balance and peripheral cholesterol and lipid metabolism [15-19]? Although the authors were unable to detect changes in norepinephrine content in the liver or adipose tissue, more detailed analysis of norepinephrine turnover or direct electrophysiological studies might be needed to reveal possible differences in sympathetic nervous system activity in specific peripheral tissues. The authors' observation that NPR-B expression in white adipose tissue was unchanged, suggests that the possible direct effect of CNP/NPRB signaling on adipogenesis can be ruled out [20].

Nevertheless, the dysregulation of this system has been associated with lifestyle-related conditions such as obesity, and it has been suggested that a "natriuretic handicap" might be an important factor in the initiation and progression of metabolic dysfunction, and obesity related co-morbidities such as hypertension [21]. Indeed, the synthesis of the cardiac oxytocin-natriuretic peptide system is reduced in ob/ob mouse model, and CNP levels have been reported to be significantly lower in obese adolescents in comparison to healthy children $[22,23]$.

In this respect, the study by Yamashita et al. expands our current understanding of the role of central CNP/NPR-B signaling in the regulation of energy balance and metabolic homeostasis. 
The observations also warrant further studies using different Creexpressing lines (possibly in conjunction with interventions and models targeting central melanocortin system) to uncover the mechanisms behind the metabolic effects of CNP/NPR-B signaling.

\section{References}

[1] S. Del Ry, C-type natriuretic peptide: a new cardiac mediator, Peptides 40 (2013) 93-98, http://dx.doi.org/10.1016/j.peptides.2012.12.010.

[2] S. Del Ry, et al., Expression of C-type natriuretic peptide and its receptor NPR-B in cardiomyocytes, Peptides 32 (2011) 1713-1718, http://dx.doi.org/ 10.1016/j.peptides.2011.06.014.

[3] D. Popovic, et al., The interface of hypothalamic-pituitary-adrenocortical axis and circulating brain natriuretic peptide in prediction of cardiopulmonary performance during physical stress, Peptides 47 (2013) 85-93, http://dx.doi. org/10.1016/j.peptides.2013.07.009.

[4] L.R. Potter, S. Abbey-Hosch, D.M. Dickey, Natriuretic peptides, their receptors, and cyclic guanosine monophosphate-dependent signaling functions, Endocr. Rev. 27 (2006) 47-72, http://dx.doi.org/10.1210/er.2005-0014.

[5] S. Suga, et al., Receptor selectivity of natriuretic peptide family, atrial natriuretic peptide, brain natriuretic peptide, and C-type natriuretic peptide, Endocrinology 130 (1992) 229-239, http://dx.doi.org/10.1210/endo.130.1. 1309330.

[6] H. Chusho, et al., Dwarfism and early death in mice lacking C-type natriuretic peptide, Proc. Natl. Acad. Sci. U. S. A. 98 (2001) 4016-4021, http://dx.doi.org/ 10.1073/pnas.071389098.

[7] N. Tamura, et al., Critical roles of the guanylyl cyclase B receptor in endochondral ossification and development of female reproductive organs, Proc. Natl. Acad. Sci. U. S. A. 101 (2004) 17300-17305, http://dx.doi.org/10. 1073/pnas.0407894101.

[8] M. Inuzuka, et al., C-type natriuretic peptide as a new regulator of food intake and energy expenditure, Endocrinology 151 (2010) 3633-3642, http://dx.doi. org/10.1210/en.2010-0141.

[9] J.P. Herman, M.C. Langub Jr., R.E. Watson Jr., Localization of C-type natriuretic peptide mRNA in rat hypothalamus, Endocrinology 133 (1993) 1903-1906, http://dx.doi.org/10.1210/endo.133.4.8404633.

[10] M.C. Langub Jr., C.M. Dolgas, R.E. Watson Jr., J.P. Herman, The C-type natriuretic peptide receptor is the predominant natriuretic peptide receptor mRNA expressed in rat hypothalamus, J. Neuroendocrinol. 7 (1995) 305-309.

[11] N. Yamada-Goto, et al., Intracerebroventricular administration of C-type natriuretic peptide suppresses food intake via activation of the melanocortin system in mice, Diabetes 62 (2013) 1500-1504, http://dx.doi.org/10.2337/ db12-0718.

[12] Y. Yamashita, et al., Brain-specific natriuretic peptide receptor-B deletion attenuates high-fat diet-induced visceral and hepatic lipid deposition in mice, Peptides 81 (2016) 38-50, http://dx.doi.org/10.1016/j.peptides.2016.03.014.
[13] E. Harno, E.C. Cottrell, A. White, Metabolic pitfalls of CNS cre-based technology, Cell Metab. 18 (2013) 21-28, http://dx.doi.org/10.1016/j.cmet. 2013.05.019.

[14] J. Declercq, et al., Metabolic and behavioural phenotypes in nestin-Cre mice are caused by hypothalamic expression of human growth hormone, PLoS One 10 (2015) e0135502, http://dx.doi.org/10.1371/journal.pone.0135502.

[15] N. Balthasar, et al., Divergence of melanocortin pathways in the control of food intake and energy expenditure, Cell 123 (2005) 493-505.

[16] J. Rossi, et al., Melanocortin-4 receptors expressed by cholinergic neurons regulate energy balance and glucose homeostasis, Cell Metab. 13 (2011) 195-204, http://dx.doi.org/10.1016/j.cmet.2011.01.010.

[17] E.D. Berglund, et al., Melanocortin 4 receptors in autonomic neurons regulate thermogenesis and glycemia, Nat. Neurosci. 17 (2014) 911-913, http://dx.doi. org/10.1038/nn.3737.

[18] D. Perez-Tilve et al, Melanocortin signaling in the CNS directly regulates circulating cholesterol, Nat. Neurosci. 13 (2010) 877-882, http://dx.doi.org/ $10.1038 /$ nn.2569.

[19] R. Nogueiras, et al., The central melanocortin system directly controls peripheral lipid metabolism, J. Clin. Invest. 117 (2007) 3475-3488.

[20] T. Katafuchi, D.L. Garbers, J.P. Albanesi, CNP/GC-B system: a new regulator of adipogenesis, Peptides 31 (2010) 1906-1911, http://dx.doi.org/10.1016/j. peptides.2010.06.025.

[21] N.E. Zois, et al., Natriuretic peptides in cardiometabolic regulation and disease. Nature reviews, Cardiology 11 (2014) 403-412, http://dx.doi.org/10. 1038/nrcardio.2014.64.

[22] T.L. Broderick, D. Wang, M. Jankowski, J. Gutkowska, Unexpected effects of voluntary exercise training on natriuretic peptide and receptor mRNA expression in the ob/ob mouse heart, Regul. Pept. 188 (2014) 52-59, http:// dx.doi.org/10.1016/j.regpep.2013.12.005.

[23] S. Del Ry, et al., C-type natriuretic peptide plasma levels are reduced in obese adolescents, Peptides 50 (2013) 50-54, http://dx.doi.org/10.1016/j.peptides. 2013.09.013.

Jari Rossi

Institute of Biomedicine/Anatomy, University of Helsinki, Helsinki, Finland E-mail address: jari.rossi@helsinki.fi

15 August 2016

15 August 2016

Available online 20 August 2016 